\title{
Secondary glioblastoma after treatment of intracranial germinoma - would radiation- only therapy still be safe? Case report
}

\author{
Kihwan Hwang ${ }^{1,4}$, Kyu Sang Lee ${ }^{2}$, Gheeyoung Choe ${ }^{2,4}$, Byung-Gyu Cho ${ }^{3}$ and Chae-Yong Kim ${ }^{1,4^{*}}$ (D)
}

\begin{abstract}
Back ground: Intracranial germinomas are one of the most radiosensitive tumors and are curable by radiotherapy (RT) alone. RT-only therapy without chemotherapy is effective. But, as patients with germinoma can expect longterm survival, the adverse effects of RT and late sequelae in survivors are of most concern. So, recently, standard treatment protocol of combination with chemotherapy and reduced dose of RT could be widely acceptable.

Case presentation: We report a patient with germinoma who developed RT-induced glioblastoma. He was diagnosed as biopsy-proven germinoma at the age of 12. Postoperatively, he underwent RT alone without chemotherapy and remained free of tumor without recurrence during long-term follow up. However, after almost 20 year, he developed RT-induced glioblastoma.

Conclusions: Although RT has the highest priority among treatments on intracranial germinomas, RT-only therapy with full dose for germinoma can have delayed severe complications. So, chemotherapy prior to reduced dose RT is more desirable.
\end{abstract}

Keywords: Germinoma, Radiotherapy, Secondary malignancy, Glioblastoma

\section{Background}

Intracranial germinomas are one of the most radiosensitive tumors and are curable by radiotherapy (RT) alone [1-3]. As patients with intracranial germinoma can expect long-term survival, the adverse effects of RT and late sequelae in survivors are inevitable. RT-induced sencodary malignancy is one of those sequelae. To the best of our knowledge, only a few cases of radiation-induced secondary tumors have been reported in germ cell tumors (GCT), especially in pure germinomas [4-6]. Herein, we describe follow-up results of a germinoma case which developed therapy-associated secondary tumor.

Intracranial germinoma have favorable cure rates. Acharya et al. reported that overall survival at 20 and 30 years for GCT was 84.1 and $61.9 \%$, respectively, and the cumulative incidence of subsequent malignancy after

\footnotetext{
* Correspondence: chaeyong@snu.ac.kr

'Department of Neurosurgery, Seoul National University Bundang Hospital,

82, Gumi-ro 173 Beon-gil, Bundang-gu, Seongnam-si, Gyeonggi-do 13620, Republic of Korea

${ }^{4}$ Seoul National University College of Medicine, Seoul, South Korea

Full list of author information is available at the end of the article
}

treatment of germinoma was $6.0 \%$ at 25 years [7]. As, late sequelae affect long-term survival, treatment protocol of combination with chemotherapy and reduced dose of RT is widely acceptable, recently [8-14]. Our case would support the change for treatment protocol of combined chemotherapy and RT.

\section{Case presentation}

A 33-year-old man presented with right facial palsy and right hand fine motor dysfunction for over previous 3 months. MRI revealed a gadolinium-enhanced mass lesion in left basal ganglia with extension to crus cerebri and left thalamus (Fig. 1). Stereotactic biopsy was performed and the lesion was identified as glioblastoma, IDH-wild type.

The past medical history revealed the patient was once diagnosed with pineal mass for almost 20 years ago in 1995, when he was a 12-year-old boy. At that time, he underwent total removal of tumor via the right occipital transtentorial approach and biopsy identified germinoma. Postoperatively, he received craniospinal irradiation 24Gy and whole-brain radiotherapy 36Gy, that is, tumor bed total 50.4Gy. He was free from tumor

(c) The Author(s). 2018 Open Access This article is distributed under the terms of the Creative Commons Attribution 4.0 International License (http://creativecommons.org/licenses/by/4.0/), which permits unrestricted use, distribution, and 


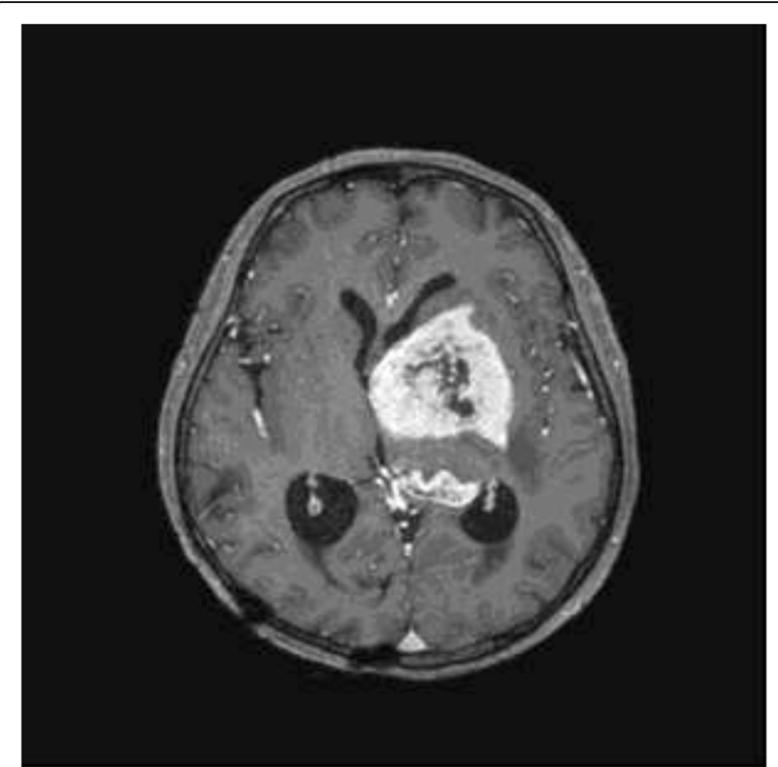

Fig. $1 \mathrm{MRI}$ demonstrated a tumor as a gadolinium-enhanced lesion in the left basal ganglia with extension to crus cerebri and thalamus

recurrence or secondary tumor until 2006, when he had the last follow-up MRI. After then, he had no MRI follow-ups until the newly-developed symptoms occur in January 2015.

Although we thought that this was evidence of tumor recurrence, biopsy identified glioblastoma, and we suspected that it was a therapy-associated tumor (Fig. 2). He received concurrent chemoradiotherapy with temozolomide. As tumor progression was identified during follow-up, he underwent bevacizumab/irinotecan and metronomic temozolomide consecutively till 15 months after the biopsy. But, the tumor progressed and he died in May 2016.

\section{Discussion and conclusions}

The authors reported secondary malignancy from GCT that occurred after cranial irradiation to emphasize careful monitoring for long-term survival for GCT. The accepted criteria to diagnose a RT induced brain tumor are well defined as follows: 1) the tumor must appear within the irradiated field; 2) the tumor was not present prior to the RT; 3) a sufficient latency period must elapse between irradiation and appearance of the tumor (usually $>5$ years); 4 ) the radiation induced tumor must be histologically proven and a different histological type from the original neoplasm treated by the radiation therapy [15]. Our cases meet all of these criteria.

Radiation-induced malignant gliomas (RIMGs) from primary germinomas are considered very rare. We searched 4 published cases from 1960 to 2016, and added our case identified at our report (Table 1) [4-6, 16-18]. Mean age was 11.2 years, and mean interval between initial tumor and RIMGs was 10.8 years. Two cases by
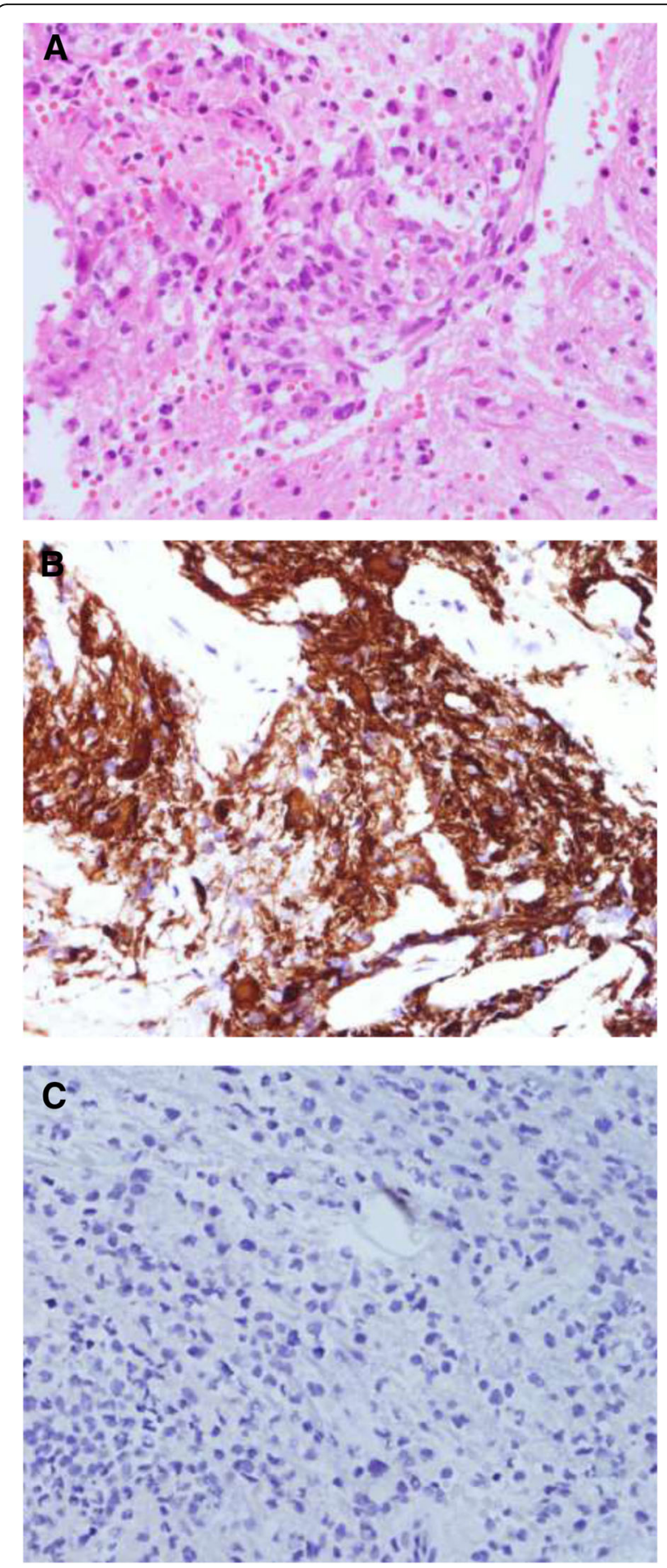

Fig. 2 Histopathological examination of the surgical specimen. (a) Hematoxylin and eosin stain $(\times 400)$ revealed a poorly differentiated malignant tumor. Immunohistochemistry stains ( $\times 400)$ were $(\mathbf{b})$ positive for GFAP and (c) negative for IDH-1

You et al. [18] and one case by Nishio et al. [17] received craniospinal irradiation and boost to tumor bed. You et al. reported a case that radiation induced tumor appear at the same location as the initial tumor, so a recurrence was misdiagnosed at first [18]. Kitanaka et al. 
Table 1 Literature Review of Cases of Radiation-Induced Malignant Gliomas (RIMGs) from Germinomas (1960-2016)

\begin{tabular}{|c|c|c|c|c|c|c|c|c|}
\hline & $\begin{array}{l}\text { Author } \\
\text { (Ref.) }\end{array}$ & Sex/Age (years) & Site & Dose (Gy) & $C T x$ & $\begin{array}{l}\text { Interval } \\
\text { (years) }\end{array}$ & $\begin{array}{l}\text { Second } \\
\text { Dx. }\end{array}$ & Site \\
\hline 1 & You [18] & $M / 8$ & $\mathrm{BG} / \mathrm{Th}$ & 50.4 & No & 9.5 & hGGTm & $\mathrm{BG} / \mathrm{Th}$ \\
\hline 2 & You [18] & $\mathrm{F} / 5$ & SS & 49.8 & Yes & 8.8 & GB & Rt. T \\
\hline 3 & Kitanaka [16] & $M / 13$ & Pineal & 54 & No & 7 & AA & Lt. T - P \\
\hline 4 & Nishio [17] & $M / 18$ & Pineal & 50 & No & 9.5 & GB & Cbll Brain stem \\
\hline 5 & Our case & $M / 12$ & Pineal & 50.4 & No & 19.4 & GB & $\mathrm{BG} / \mathrm{Th} \sim$ Brain stem \\
\hline
\end{tabular}

BG basal ganglia, Th thalamus, $h G G T m$ high-grade glial tumor, SS suprasella, GB glioblastoma, $A A$ anaplastic astrocytoma

reported a case of 13-year-old boy whose pineal mass was diminished in size with a diagnostic radiation of 20 Gy. Such a susceptibility to radiation confirmed the diagnosis of germinoma, and another 34 Gy was delivered to the whole brain [16].

Germinoma is considered as one of the most radiosensitive tumors and are curable by RT alone $[1,11,19]$. Although RT has had the highest priority among treatments on intracranial germinomas, agreement with respect to treatment volume, dose, and use of chemotherapy has not been reached. Ogawa et al. [1] reviewed 126 patients with intracranial germinoma and said that higher total doses were effective in preventing intracranial relapse. Haddock et al. [19] reported whole-brain or craniospinal axis irradiation appears to result in fewer spine and brain failures than dose partial-brain irradiation. But, the risk of developing a secondary brain tumor increases with increasing irradiation dose [20]. There have been many efforts to develop minimum effective radiation dose for germinoma, but the optimal radiation dose and its potential to cause secondary tumor have always been difficult to reach conclusion.

Radiation-induced CNS neoplasms are rare, but the cumulative risk of brain tumor after therapeutic cranial irradiation is reported as up to $2.7 \%$ at 15 years [21]. Furthermore, Acharya et al. reported that at 25 years, the cumulative incidence of subsequent malignancy after treatment of germinoma was 6.0\% [7]. Although RT has the highest priority among treatments on intracranial germinomas, RT-only therapy has the possibility of second primary tumor.

As an effort to reduce dose of RT has begun after the mid-2000s [22-24] and the prognosis of primary germinoma is relatively good, we will face more to the second primary tumors during long-term follow up. As our case revealed, secondary malignancy is possible even after 20 year follow-up. So, when new lesions are developed, especially long period after initial irradiation, we should doubt the chance of radiation-induced secondary tumors. Proper evaluation for new symptoms should be emphasized to the patients and their family, and the pathologic confirmation of a new lesion is important in planning optimal treatment plan.
We document the development of therapy-associated secondary brain tumors in a patient with germinoma who underwent primary tumor resection and postoperative RT without chemotherapy. RT-only therapy without chemotherapy for germinoma is effective, but radiation-induced secondary tumors are possible during long-term follow up, even about 20 years after primary tumor like in our case. So, Patients with germinoma who had only postoperative RT without chemotherapy should be carefully monitored.

\section{Abbreviations}

GCT: Germ cell tumors; IDH: Isocitrate dehydrogenase; MRI: Magnetic resonance imaging; RIMGs: Radiation-induced malignant gliomas; RT: Radiotherapy

\section{Acknowledgements \\ None. \\ Funding \\ None.}

\section{Availability of data and materials}

Data for this case report were collected by chart review of the patient's electronic medical record, which is not publicly available due to privacy considerations.

\section{Authors' contributions}

Substantial contributions to conception and design (KCY, CBK), collection of data (HKH, KCY, LKS, CGY), analysis and interpretation of data (HKH, LKS, CGY), preparation of the manuscript $(\mathrm{HKH})$ and supervision (CBK, KCY) were carried out. All authors read and approved the final manuscript.

\section{Ethics approval and consent to participate}

The study was approved by the institutional review boards of Seoul National University Bundang Hospital (B-1709/421-701). We confirm that we have read the Journal's editorial policies involved in ethical publication and affirm that this report is consistent with those guidelines.

\section{Consent for publication}

Informed written consent to publish data and images was obtained from the mother of the patient.

\section{Competing interests}

The authors declare that they have no competing interests.

\section{Publisher's Note}

Springer Nature remains neutral with regard to jurisdictional claims in published maps and institutional affiliations.

\section{Author details}

'Department of Neurosurgery, Seoul National University Bundang Hospital, 82, Gumi-ro 173 Beon-gil, Bundang-gu, Seongnam-si, Gyeonggi-do 13620, Republic of Korea. ${ }^{2}$ Department of Pathology, Seoul National University 
Bundang Hospital, 82, Gumi-ro 173 Beon-gil, Bundang-gu, Seongnam-si, Gyeonggi-do 13620, Republic of Korea. ${ }^{3}$ Department of Neurosurgery, Korean Armed Forces Capital Hospital, Seongnam-si, South Korea. ${ }^{4}$ Seoul National University College of Medicine, Seoul, South Korea.

\section{Received: 22 September 2017 Accepted: 12 November 2018}

\section{Published online: 16 November 2018}

\section{References}

1. Ogawa K, Shikama N, Toita T, Nakamura K, Uno T, Onishi H, Itami J, Kakinohana Y, Kinjo T, Yoshii Y, et al. Long-term results of radiotherapy for intracranial germinoma: a multi-institutional retrospective review of 126 patients. Int J Radiat Oncol Biol Phys. 2004;58(3):705-13.

2. Shibamoto Y, Sasai K, Oya N, Hiraoka M. Intracranial germinoma: radiation therapy with tumor volume-based dose selection. Radiology. 2001;218(2):452-6.

3. Yen SH, Chen YW, Huang PI, Wong TT, Ho DM, Chang KP, Liang ML, Chiou $\mathrm{SH}$, Lee YY, Chen HH. Optimal treatment for intracranial germinoma: can we lower radiation dose without chemotherapy? Int J Radiat Oncol Biol Phys. 2010;77(4):980-7.

4. Elsamadicy AA, Babu R, Kirkpatrick JP, Adamson DC. Radiation-induced malignant gliomas: a current review. World Neurosurg. 2015;83(4):530-42.

5. Salvati M, D'Elia A, Melone GA, Brogna C, Frati A, Raco A, Delfini R. Radioinduced gliomas: 20-year experience and critical review of the pathology. J Neuro-Oncol. 2008;89(2):169-77.

6. Salvati M, Frati A, Russo N, Caroli E, Polli FM, Minniti G, Delfini R. Radiationinduced gliomas: report of 10 cases and review of the literature. Surg Neurol. 2003;60(1):60-7 discussion 67.

7. Acharya S, DeWees T, Shinohara ET, Perkins SM. Long-term outcomes and late effects for childhood and young adulthood intracranial germinomas. Neuro-Oncology. 2015;17(5):741-6.

8. Jensen AW, Laack NN, Buckner JC, Schomberg PJ, Wetmore CJ, Brown PD. Long-term follow-up of dose-adapted and reduced-field radiotherapy with or without chemotherapy for central nervous system germinoma. Int J Radiat Oncol Biol Phys. 2010;77(5):1449-56.

9. Khatua S, Dhall G, O'Neil S, Jubran R, Villablanca JG, Marachelian A, Nastia A, Lavey R, Olch AJ, Gonzalez I, et al. Treatment of primary CNS germinomatous germ cell tumors with chemotherapy prior to reduced dose whole ventricular and local boost irradiation. Pediatr Blood Cancer. 2010;55(1):42-6.

10. Kretschmar C, Kleinberg L, Greenberg M, Burger P, Holmes E, Wharam M. Pre-radiation chemotherapy with response-based radiation therapy in children with central nervous system germ cell tumors: a report from the Children's oncology group. Pediatr Blood Cancer. 2007;48(3):285-91.

11. Osuka S, Tsuboi K, Takano S, Ishikawa E, Matsushita A, Tokuuye K, Akine Y, Matsumura A. Long-term outcome of patients with intracranial germinoma. J Neuro-Oncol. 2007;83(1):71-9.

12. Murray MJ, Bartels U, Nishikawa R, Fangusaro J, Matsutani M, Nicholson JC Consensus on the management of intracranial germ-cell tumours. Lancet Oncol. 2015:16(9):e470-7.

13. Diez B, Balmaceda C, Matsutani M, Weiner HL. Germ cell tumors of the CNS in children: recent advances in therapy. Childs Nerv Syst. 1999;15(10):578-85.

14. Rogers SJ, Mosleh-Shirazi MA, Saran FH. Radiotherapy of localised intracranial germinoma: time to sever historical ties? Lancet Oncol. 2005; 6(7):509-19.

15. Cahan WG, Woodard $\mathrm{HQ}$, et al. Sarcoma arising in irradiated bone; report of 11 cases. Cancer. 1948;1(1):3-29.

16. Kitanaka C, Shitara N, Nakagomi T, Nakamura H, Genka S, Nakagawa K, Akanuma A, Aoyama H, Takakura K. Postradiation astrocytoma. Report of two cases. J Neurosurg. 1989;70(3):469-74.

17. Nishio S, Morioka T, Inamura T, Takeshita I, Fukui M, Sasaki M, Nakamura K, Wakisaka S. Radiation-induced brain tumours: potential late complications of radiation therapy for brain tumours. Acta Neurochir. 1998;140(8):763-70

18. You SH, Lyu CJ, Kim DS, Suh CO. Second primary brain tumors following cranial irradiation for pediatric solid brain tumors. Childs Nerv Syst. 2013; 29(10):1865-70

19. Haddock MG, Schild SE, Scheithauer BW, Schomberg PJ. Radiation therapy for histologically confirmed primary central nervous system germinoma. Int J Radiat Oncol Biol Phys. 1997;38(5):915-23.

20. Walter AW, Hancock ML, Pui CH, Hudson MM, Ochs JS, Rivera GK, Pratt CB, Boyett JM, Kun LE. Secondary brain tumors in children treated for acute lymphoblastic leukemia at St Jude Children's research hospital. J Clin Oncol. 1998;16(12):3761-7.
21. Paulino AC, Mai WY, Chintagumpala M, Taher A, Teh BS. Radiation-induced malignant gliomas: is there a role for reirradiation? Int J Radiat Oncol Biol Phys. 2008;71(5):1381-7.

22. Matsutani M, Japanese pediatric brain tumor study G. Combined chemotherapy and radiation therapy for CNS germ cell tumors--the Japanese experience. J Neuro-Oncol. 2001;54(3):311-6.

23. Eom KY, Kim IH, Park Cl, Kim HJ, Kim JH, Kim K, Kim SK, Wang KC, Cho BG, Jung HW, et al. Upfront chemotherapy and involved-field radiotherapy results in more relapses than extended radiotherapy for intracranial germinomas: modification in radiotherapy volume might be needed. Int J Radiat Oncol Biol Phys. 2008;71(3):667-71.

24. Calaminus G, Kortmann R, Worch J, Nicholson JC, Alapetite C, Garre ML, Patte C, Ricardi U, Saran F, Frappaz D. SIOP CNS GCT 96: final report of outcome of a prospective, multinational nonrandomized trial for children and adults with intracranial germinoma, comparing craniospinal irradiation alone with chemotherapy followed by focal primary site irradiation for patients with localized disease. Neuro-Oncology. 2013;15(6):788-96.

\section{Ready to submit your research? Choose BMC and benefit from:}

- fast, convenient online submission

- thorough peer review by experienced researchers in your field

- rapid publication on acceptance

- support for research data, including large and complex data types

- gold Open Access which fosters wider collaboration and increased citations

- maximum visibility for your research: over $100 \mathrm{M}$ website views per year

At BMC, research is always in progress.

Learn more biomedcentral.com/submissions 